\title{
La cultura de convergencia digital y la inclusión sociocultural: Interconectando formación y práctica docente
}

\section{Digital convergence culture and sociocultural inclusion: interconnecting training and teaching practice}

\author{
Adriana Moreira Da Rocha ${ }^{1}$ \\ adrianaufsm@gmail.com \\ Doris Pires VARGas Bolzan \\ dbolzan19@gmail.com \\ Universidade Federal de Santa Maria, Brasil
}

\section{Resumen:}

Este artículo está basado en una investigación cualitativa, del tipo estudio de caso, sobre las probables implicaciones de la cultura de convergencia digital y tecnológica, en la construcción de los saberes docentes y en el aprendizaje de la docencia digital. Se sustenta en aportes teórico conceptuales, interrelacionando dos ejes argumentativos: la formación inicial de profesores en la Universidad y la práctica docente de los egresos en la Escuela Básica. El escenario investigativo es el curso de licenciatura en pedagogía, cuyos protagonistas se constituyen profesores de la nueva generación digital y los niños nacidos en el Siglo XXI. Explicitar las implicaciones de la cultura de convergencia digital trae nuevas perspectivas a la planificación y desarrollo de los procesos de enseñar y aprender, por medio de ambientes pedagógicos y de coreografías digitales que permiten la integración de

\begin{abstract}
:
This study is based on a qualitative research, a case study type, about the prospective implications of digital and technological convergence culture on teaching knowledge and on digital teaching learning. It is based on theoretical-conceptual examples, making an interrelation of two argumentative axis: the initial training of teachers in the University and the teaching practice of graduate students in elementary school. The research scenario is the Pedagogy Degree, whose main characters are new generation teachers and 21 st century children. Knowing the implications of convergence culture brings new perspectives on planning and developing processes of teaching and learning through the use of pedagogical ambiences and digital choreographies which allow the integration of digital technologies of information and communication (DTIC) and the World Wide Web (hy-
\end{abstract}

1 Dirección para correspondencia (correspondence address):

Adriana Moreira Da Rocha Veiga. Departamento de Fundamentos da Educaçao. Centro de Educaçao. Universidade Federal de Santa Maria. Cidade Universitária. Av. Roraima n. ${ }^{\circ}$ 1000. Bairro Camobi. Santa Maria - RS. CEP: 97105-900. Santa Maria, ES (Brasil). 
La cultura de convergencia digital y la inclusión sociocultural: Interconectando formación y práctica docente

adriana Moreira Da Rocha y Doris Pires Vargas Bolzan

las tecnologías digitales de la información y comunicación (TDIC) y del propio Word Wide Web (sistema hipertextual accionado en red mundial vía Internet). Se concluye que la formación universitaria en ambiente pedagógico digital es fundamental para la construcción de los nuevos saberes docentes de las TDIC y de la Web, favoreciendo la consolidación de la fluidez pedagógica y tecnológica. En la escuela, tal ambiente parece depender más de profesores fluentes, de lo que de la transferencia de tecnologías de última generación. Prácticas educativas convergentes en la educación requieren continuidad entre formación inicial y experiencia docente, integradas a la experiencia pedagógica hipermedia. En síntesis, el proceso constitutivo de ser profesor envuelve la apropiación de la cultura de convergencia digital y tecnológica, lo que nos desafía a nuevos postulados a la formación de profesores.

\section{Palabras clave:}

Formación de profesores; enseñanza y formación; enseñanza multimedia; aprendizaje de enseñanza virtual; estrategia de enseñanza. pertextual system used in world web on the Internet). The conclusion of this study is that higher education training in digital pedagogical ambience is important when building teaching knowledge in DTCl and WEB, which supports the consolidation of pedagogical and technological fluency. In schools, this ambience relies more often on confluent teachers than on the transference of last generation technologies. Educational convergent practices require continuity between initial training and teaching experience, a continuity that also needs to be integrated into hypermediatic pedagogical experience. In summary, the constitutive process of being a teacher involves the appropriation of digital and technological convergence culture, which challenges us to new postulates on teaching training.

\section{Key words:}

Teacher training; multimedia teaching; virtual teaching learning; teaching strategy; digital pedagogical ambience.

\section{Resumo:}

Este artigo decorre de pesquisa qualitativa, com abordagem descritivo-interpretativa das prováveis implicações da cultura de convergência digital na construção dos saberes docentes e na aprendizagem da docência. Sustenta-se em aportes teórico-conceituais, inter-relacionando dois eixos argumentativos: a formação inicial de professores na Universidade e a prática docente dos egressos na Escola Básica. O cenário investigativo são os cursos de licenciatura, voltados à formação de professores para a nova geração digital, constituída por crianças e jovens nascidos no Século XXI. Ao explicitar as implicações da cultura de convergência traz novas perspectivas para a planificação e desenvolvimento dos processos de ensinar e aprender, por meio de ambientes e estratégias pedagógicas que permitem a integração das tecnologias digitais da informação e comunicação (TDIC) e do próprio World Wide Web, sistema hipertextual acionado em rede mundial via Internet. Conclui-se acerca da importância da formação universitária em ambiência pedagógica digital para a construção dos novos saberes docentes acerca das TDIC e da Web, referentes à fluência pedagógica e tecnológica do professor. Na escola, tal ambiência parece depender mais de professores fluentes do que da transferência de tecnologias de última geração, destacando-se a importância da aprendizagem da docência digital. As práticas educativas requerem ainda continuidade entre formação inicial e experiência docente, integradas na experiência pedagógica hipermidiática. Em síntese, o processo constitutivo de ser professor envolve a apropriação ativa das tecnologias, desafiando a educação e a formação de professores para novos postulados.

\section{Palavras-chaves:}

Formação de professores; docência e formação; docência multimídia; aprendizagem da docência virtual; estratégia de ensino. 
Fecha de recepción: 6-1-2015

Fecha de aceptación: 10-9-2015

\section{Introdução}

Este artigo apresenta resultados parciais da pesquisa intitulada "Cultura de convergência digital nos cursos de licenciatura da UFSM: é possível uma conexão (trans)formativa entre a Educação Superior e a Educação Básica?" ${ }^{2}$. Desde 2011, vimos desenvolvendo nossos estudos nos cursos de licenciatura ${ }^{3}$ e nas escolas públicas de educação básica, contextos intercomplementares em suas práticas, sendo notórias as implicações da cultura de convergência digital para a construção dos saberes docentes e para a aprendizagem da docência. Esses resultados são corroborados pelos resultados da pesquisa "Aprendizagem da docência: processos formativos de estudantes e formadores da educação superior" ${ }^{\prime \prime}$, aqui compartilhados em processo colaborativo de reflexão crítica. Esses conhecimentos tornam conscientes modelos teóricos e epistemológicos que se evidenciam nos processos formativos e, ao mesmo tempo, favorecem a compreensão da aprendizagem de ser professor e da aprendizagem de ser professor na cultura de convergência digital.

A sequência das pesquisas e o avanço teórico da área de educação e interface com as tecnologias trazem a urgência de se compreender as inter-relações entre a formação inicial dos licenciandos, a formação permanente dos formadores e a apropriação das Tecnologias Digitais da Informação e Comunicação (TDIC adiante) ${ }^{5}$ e da Web nos processos formativos e nas incursões na Escola Básica. A partir da cultura de convergência digital, configuram-se no contemporâneo novas formas de lidar com as informações e, consequentemente de produzir conhecimentos,

2 Estudos desenvolvidos pelo Grupo de Pesquisa em Educação Digital e Redes de Formação, liderado por Adriana Moreira da Rocha Veiga - UFSM/PPGE/CNPq.

3 No Brasil os cursos de licenciatura habilitam o seu titulado a ser professor da educação básica, em escolas de Ensino Infantil, Ensino Fundamental e Ensino Médio.

4 Estudos liderados por Doris Pires Vargas Bolzan no Grupo de Pesquisa Formação de Docentes e Práticas Educativas: ensino básico e superior - UFSM/PPGE/CNPq.

5 O conceito de Tecnologias Digitais da Informação e da Comunicação - TDIC, considera o universo digital interativo e os processadores, cujo código de máquina é representado pelo sistema binário, em que todas as quantidades têm base em dois números: zero e um (0 e 1) (Lévy, 2009). Neste contexto, a Web 2.0 e a Web 3.0 são movimentos naturais do desenvolvimento tecnológico. 
provocando a [re]construção da docência, sob novos paradigmas e saberes convergentes. Logo, é preciso compreender se estão ocorrendo e como se configuram os processos de convergência nos cursos de licenciatura e na transposição do letramento midiático dos licenciandos e dos egressos para as suas práticas educativas na Educação Básica.

O avanço das questões pedagógicas e tecnológicas na construção dos saberes docentes envolve a compreensão das relações recíprocas entre o domínio do saber (conhecimento científico), o domínio do saber fazer (conhecimento prático) e o domínio do saber e do saber fazer na cultura digital (conhecimento tecnológico). Assim, o processo de pensar e as formas de conceber e de desenvolver o ensino explicita como se reorganizam professores formadores e professores em formação (estudantes das licenciaturas) diante dos desafios para uma nova escola, a ser desenhada para os aprendentes do Século XXI, considerando-se os seus modos diversificados de aprender.

As autoras, partindo de pesquisa qualitativa compartilhada, constroem a reflexão crítica a partir dos resultados já apurados do estudo de casos em que se debruçam, indagando sobre a ressonância da cultura de convergência ${ }^{6}$ (CC adiante) na (re) construção dos saberes da docência na educação superior, considerando novas possibilidades de aprendizagem da docência nos processos formativos dos licenciandos. A CC poderia levar a uma reorganização do ensino e dos ambientes pedagógicos presenciais, pela inclusão sociodigital e pelo letramento midiático?

O horizonte interpretativo dos achados de pesquisa parte da ideia de que a CC pode estimular novas pedagogias e ambiências pedagógicas permeáveis à inclusão sociodigital, compreendendo e respondendo às demandas da Educação no Século XXI. Prospectivamente aponta para uma educação convergente, na qual aprendentes nativos, nascidos em uma cultura digital e ensinantes imigrantes da cultura analógica, tornam possível a aprendizagem da docência digital em interação.

\section{Argumentação teórica}

Pierre Lèvy (2009, p.144) sublinha a velocidade do surgimento e da renovação dos saberes e de savoir-faire: "toda e qualquer reflexão séria

6 Conceito adotado a partir de Jenkins (2009), compreendido por ele como um novo paradigma para entender a transformação midiática. 
sobre o devir dos sistemas de educação e formação na cibercultura deve apoiar-se numa análise prévia da mutação contemporânea da relação com o saber". E a relação com o saber tem sido predominantemente bancária, no bom dizer de Paulo Freire (1987). É muito fácil acessar a Web com a mesma intenção bancária ou utilizar as tecnologias digitais em aula do mesmo modo com que se utilizaria um quadro de giz para passar o texto e o exercício de aplicação.

A integração dos saberes das TDIC e da Web (Barbiero, 2013) na convergência entre dispositivos tecnológicos virtuais e presenciais pode transferir tecnologias específicas às áreas de conhecimento envolvidas na formação docente e imprimir aos processos de aprendizagem a mediação de tecnologias cognitivas. Ao constatar-se a reconstrução dos saberes docentes frente à convergência digital, inferiu-se a necessidade de compreender se estão ocorrendo e como se configuram os processos de convergência nos cursos de formação inicial de professores e na transposição do letramento midiático do licenciando e do egresso para as suas práticas educativas na Educação Básica.

As experiências de convergência, culturais e pedagógicas, dos docentes e discentes nos cursos de formação de professores, em ambientes digitais contribuiriam para a construção de novos saberes docentes. Infere-se ainda que a apropriação desses saberes repercutiria positivamente na Educação Básica, viabilizando a inclusão sociodigital dos estudantes dos sistemas públicos de ensino, nos níveis básico, técnico, tecnológico e superior.

Em um país como Brasil, de diversidade social e cultural em sua vasta expansão territorial, com regiões notadamente defasadas, as iniciativas de inclusão digital perpassam a necessidade de inclusão social. Mesmo em regiões mais desenvolvidas como sudeste e sul do país podem ser observadas disparidades e carências socioeducacionais de impacto relevantes, A despeito disso, corrobora o fato de a necessidade das tecnologias digitais na educação ainda não serem uma lógica política, estratégica e educacional, tanto para a universidade quanto para a escola. Consequentemente, a fusão dos dois termos, social e digital, representa assumir que não se trata apenas de acessibilidade às tecnologias digitais, mas também de educação tecnológica em diferentes níveis de domínio do conhecimento, de acordo com as necessidades específicas das pessoas envolvidas e das possibilidades de o programa responder às expectativas e prioridades de formação. A contramão disso seria uma inclusão di- 
La cultura de convergencia digital y la inclusión sociocultural: Interconectando formación y práctica docente

Adriana Moreira Da Rocha y Doris Pires Vargas Bolzan

gital que basicamente fornecesse acesso a um computador com Internet e treinasse apenas o uso básico dessa ferramenta. Repensar a educação no paradigma da inclusão sociodigital, requer trazer os docentes para a cultura da convergência digital e tecnológica, apropriando-se e dando acesso na prática educativa aos instrumentos de mediação sociocultural (Vygotski, 1993, 1995) que permitem o protagonismo e a qualidade de vida, tornando efetivamente melhor a vida das pessoas.

As crianças e jovens do Século XXI, identificadas por Prensky (2010) como Nativos Digitais, já nascem em um mundo digital, habituando-se com as Tecnologias Digitais em suas vidas. Os adultos são imigrantes digitais, pois não tiveram acesso imediato a essas tecnologias, apresentando dificuldades ao manuseá-las, ou em vê-las como mediadoras para o desenvolvimento da aprendizagem. Consequentemente, os estudantes são, em sua maioria, nativos digitais, enquanto seus professores ainda não assumiram um posicionamento coeso diante da cultura digital. Enquanto muitos já são imigrantes com cidadania digital, outros permanecem alheios ou até negam essa possibilidade, como resistência ao novo que se impõe na educação. Os argumentos resistentes que levam as tecnologias digitais para o status de recursos educacionais ou ferramentas tecnológicas dispensáveis são passíveis de refutação ao trazer as tecnologias digitais para a educação como instrumentos de mediação sociocultural às aprendizagens, compreendendo-as, portanto, como tecnologias cognitivas.

No entanto, todos vivem hoje a cultura de convergência digital em diferentes âmbitos da vida pessoal, social e profissional, sendo possível argumentar que educadores letrados tecnologicamente como profissionais atentos às mudanças educacionais, podem apoiar os estudantes a desenvolver ao máximo as suas habilidades no uso dos dispositivos digitais, redes de informação, mídia digital e outras tecnologias, considerando os objetivos de aprendizagem e o gerenciamento social e individual das informações. Também se argumenta a favor da apropriação ativa da cultura de convergência digital nos processos formativos iniciais dos estudantes das licenciaturas e, consequentemente, na formação permanente dos formadores; formação compreendida como autotransformação, pontualmente pela reconstrução da docência, agregando os saberes das TDIC e Web como porta de entrada para o advento de tecnologias cognitivas mais complexas.

Os professores, imigrantes digitais, foram educados para a permanên- 
cia, estabilidade e valores pretensamente duráveis para toda a vida. E a realidade que se vive é outra. A cultura contemporânea, digital e tecnológica, em sua perspectiva globalizada e descentralizada, apresenta-se preeminente no desenvolvimento e na aprendizagem das crianças e adolescentes. Uma geração digital, diferente, multifocada, multifuncional, (hiper)ativa, irreverente e conectada, nem sempre compreendida, porque não se enquadra nos moldes da escola, impressa ainda no estilo de ensino tradicional preponderante do passado e reproduzido pelos cursos de formação de professores.

A cultura digital se constitui atualmente importante processo motivacional para romper com a educação tradicional, pelo deslocamento tempo-espaço nas informações e disseminação dos conhecimentos e também pelo aporte das TDIC e da WEB como possibilidades de interação e comunicação (Castells, 1999, 2013). Estas perspectivas redimensionam os conceitos de ensino e de aprendizagem e, consequentemente de professor e de aluno e quais sejam os seus papéis no espaço-tempo educativo da ambiência escolar.

Esta ambiência configura-se nas condições objetivas, subjetivas e intersubjetivas que configuram a escola como lugar/território de transformação. Então, pode-se pensar em ambiências escolares (trans) formativas (Maciel, 2006, 2009, 2010; Maciel \& Trevisan, 2013) que possam interagir com a cultura de convergência digital eminente na sociedade contemporânea, na qual nasceram as crianças e adolescentes que pretensamente são educadas na Educação Básica. É para essa realidade que também se ambiciona formar os professores nas universidades.

As TDIC e a Web nos trazem uma possibilidade descentralizadora, para além do simples uso como ferramenta tecnológica ou didática. Como tecnologia cognitiva envolve muito mais, envolve aprendizagem colaborativa ${ }^{7}$, diálogo, novos canais de informações, novos ambientes de aprendizagem (virtuais e presenciais). Envolve também um nível de investigação mais profunda, que vai além da constatação do uso ou não

7 Aprendizagem colaborativa caracteriza-se pela atividade compartilhada. Refere-se às trocas entre pares/docentes/discentes que permitem o aprofundamento sobre temas trabalhados coletivamente, implicando na autonomia dos sujeitos envolvidos nesse processo, permitindo-lhes, a partir da reestruturação individual dos seus esquemas de conhecimento resolver diferentes situações didático-pedagógicas e profissionais. O compartilhar de ideias, inquietações, dúvidas e ajuda pressupõe a atividade colaborativa, favorecendo o avanço do processo formativo em andamento. (Bolzan, 2002, 2009). 
das ferramentas tecnológicas na educação. Nessa direção, buscamos caminhos para a integração de hipermeios, considerando as práticas pedagógicas nos cursos de formação de professores e, consequentemente, nas escolas de educação básica. A convergência digital permite aos indivíduos o acesso ao mundo via informação, mas também permite que esse mesmo mundo acesse o indivíduo. As tecnologias digitais, como instrumentos mediadores, permitem que uma pessoa esteja conectada e se aproprie das informações desejadas ou mesmo, ainda que esta pessoa possa ser encontrada em qualquer lugar, além da possibilidade de com ela interagirem ou sobre ela adquirirem informações.

Então, qual o significado que se deseja imprimir ao termo convergência digital no contexto da pesquisa? A partir de Jenkins (2009, p. 29), compreende-se que "convergência é uma palavra que consegue definir transformações tecnológicas, mercadológicas, culturais e sociais, dependendo de quem está falando e do que imaginam estar falando". O autor refere-se ao fluxo de informações e cooperação por meio de múltiplos suportes e mercados midiáticos, bem como ao comportamento migratório dos usuários entre os meios de comunicação, principalmente em busca das experiências de entretenimento que desejam. Tudo isto vai cultivando as bases de uma nova cultura, na qual as novas gerações são produzidas, nascem e se desenvolvem.

Enfim, pode-se afirmar que convergência digital é uma tendência representada pela integração inteligente dos sistemas de informação e comunicação, resultando em uma síntese de serviços, recursos e informações capazes de prover diversos meios à sociedade. Significativas transformações culturais ocorrem à medida que os meios digitais convergem, integrando sistemas e permitindo o acesso à informação e comunicação. A cultura de convergência digital, está mudando o modo de se encarar a produção de conteúdo em todo o mundo e em diversos meios culturais, como a literatura, o cinema, a música.

O oceano digital de informações e possibilidades interativas é um desafio à educação, pois pode quebrar as barreiras da distância, ligar o máximo de dispositivos disponíveis de forma a constituir uma rede virtual colaborativa, onde idealmente todos possam estar conectados. Pode também gerar dispersão e confusão em um oceano de dados dispersos, quando não existe o gerenciamento social e pessoal (Lèvy, 2013) que filtre a navegação para fins formativos e humanísticos. O autor destaca o alto potencial semântico da Web e a necessidade de saber navegar nes- 
se oceano de sentidos e significados. Outro aspecto importante, é que para determinadas situações de inclusão todas as pessoas teriam acesso quase que instantaneamente, direta ou indiretamente, mesmo sem ter conhecimento disso. Porém, a inclusão sociodigital ainda não é uma realidade posta, senão uma possibilidade em aberto.

Tendo-se como premissa que a CC pode estimular novas pedagogias e ambiências pedagógicas digitais, defende-se a possibilidade de inclusão pelo acesso tecnológico articulado ao letramento digital. Para Buckingham (2010, p.49), "o letramento digital é bem mais do que uma questão funcional de aprender a usar o computador e o teclado, ou fazer pesquisas na Web, ainda que seja claro que é preciso começar com o básico". É preciso saber como localizar e selecionar material - como usar os navegadores, hyperlinks, os mecanismos de procura etc. Inclusive, avaliar e usar a informação de forma crítica, se o desejo for transformá-la em conhecimento. Implica questionar, indagar sobre as fontes dessa informação, "os interesses de seus produtores e as formas como ela representa o mundo, compreendendo como estes desenvolvimentos tecnológicos estão relacionados a forças sociais, políticas e econômicas mais amplas" (Idem).

$\mathrm{O}$ advento da cultura de convergência digital parece ser importante cenário motivacional para a ruptura com a educação tradicional. É uma tendência o entendimento que o aporte das TDIC e da WEB são possibilidades interativas e comunicativas de importante significado para a formação docente na universidade e na escola. No entanto, isto se efetivará quando a educação, em todos os seus níveis e modalidades, assumir as tecnologias digitais como instrumentos socioculturais de acesso ao mundo cognitivo dos aprendizes, permitindo mediações semióticas com significação para o aprendizado, ou seja, são "instrumentos de mediação sociocultural" (Vygotski, 1989, 1993) nos processos formativos iniciais e ao longo da vida, facilitando ao professor a reflexão na/sobre a sua prática. O reconhecimento desse lugar redefinirá o papel da educação no espaço-tempo da ambiência, seja ela universitária ou escolar, tornando-se território apropriado de inclusão social, onde o digital é meio e não fim; onde o humano é o fim e o [re]começo.

Aprofundando novas perspectivas conceituais para o processo ensino-aprendizagem, argumenta-se a partir da metáfora das coreografias de ensino, partindo-se dos passos da dança à planificação da aprendizagem, com a intencionalidade de interconectar a formação e a prática mediadas pela inclusão sociodigital. 
Com o termo coreografias de ensino, Baeriswyl (2008) constrói uma metáfora para a planificação da aprendizagem. A coreografia artística consiste de uma determinada sequência de passos de dança, correspondendo às etapas de aprendizagem. Tanto os dançarinos como os estudantes têm uma "paleta inteira de elementos artísticos livres, que ele pode inserir por si mesmo" (p.4). O estudante vai assimilando/acomodando/ compreendendo a estrutura profunda dos conteúdos de aprendizagem (música). A metáfora enfatiza a dinâmica que surge e mantém o aprendizado em padrões complexos.

A ideia da metáfora é que cada sequência da aprendizagem escolar/ acadêmica seja baseada em uma coreografia que se liga, por um lado, à liberdade de método, escolha de forma social e certa improvisação, por outro lado, ao rigor relativo das medidas que são absolutamente necessárias na atividade de interiorização da aprendizagem. Tal hipótese exige uma operacionalização dupla: (a) do ponto de vista da relação entre os modelos-base e a estrutura visível e (b) do ponto de vista, de um lado, do personagem ligado à regra já referida e, do outro lado, da liberdade para simular. Outras coreografias semelhantes podem ser fundadas em processos de aprendizagem significativa, por exemplo, por demonstrações, definições, ou ainda, na estimulação para que os participantes de um evento dialógico reflitam sobre sua própria prática.

Da mesma forma que na atividade de estudo abordada pela escola sociocultural (Davídov \& Markóva, 1987), em cada uma das situações coreográficas de aprendizagem, uma linha visível de ações pode ser identificada (a estrutura visível mencionada anteriormente), embora os processos coreográficos possam ser movimentados pela pluralidade criativa, não prescindem de estrutura. Persiste a consciência de que as sequências visíveis da atividade coreográfica são baseadas em regras, ou acoplamento de etapas de aprendizagem ou elementos de aprendizagem (os modelos-bases). Os aprendizes primeiro imaginam uma sequência de ações, independentemente da estrutura visível do ensino (discutindo, dizendo, oferecendo, demonstrando, etc) e, então, verificam a adequabilidade de suas sequências em retrospectiva. Tais sequências - preconcebendo ações, subsequentemente, avaliando-as e, então, repetidamente praticando-as - são os tipos de operações a serem definidas. Elas não são visualizadas, "podendo ser inferidas somente a partir da estrutura visível, porém podem ser descritas como movimentos mentais" (Oser \& Baeriswyl, 2001, p. 1043). 
Nesse nível de imersão na atividade digital de estudo, pode-se referir às tecnologias como cognitivas. De acordo com Buckingham (2010, p.45), alguns jogos digitais, exemplificando, ativam uma variada série de atividades cognitivas, tais como "lembrar, testar hipóteses, prever e usar planos estratégicos". Embora a imersão profunda no mundo virtual, o diálogo e a interação com outros participantes façam parte do próprio jogo. "O uso de games é também uma atividade de multiletramento: geralmente envolve a interpretação de complexos ambientes visuais tridimensionais, leitura tanto de texto on-screen quanto off-screen (tais como jogos/games, revistas e sites da Internet) e processamento de informações auditivas".

Esta atividade consiste em muito mais do que isto: as múltiplas possibilidades que as tecnologias cognitivas engendradas a partir das TDIC e da Web podem trazer à educação e aos educadores. Ou seja, como se pode aprender com as tecnologias de modo mais profundo e significativo, disponibilizando-as em suas possibilidades criadoras como instrumentos socioculturais.

O lúdico é inconteste na mediação pedagógica escolar. Elkonin (1998) e Vygotski (2003) destacam as experiências pessoais de criação e imaginação presentes no jogo como situação imaginária, constituídas a partir das relações interpessoais e como manifestação das condições concretas do sujeito. O conceito de "zona eminente" permite a interpretação de que os sujeitos constroem e vivenciam situações lúdicas virtuais ressonantes às suas existências concretas. Essa possibilidade é viabilizada em uma ambiência pedagógica rica em hipermídias como possibilidades de mobilização dos ensinantes/aprendentes em atividades de estudo mediadas pelo computador. As hipermídias configuram-se na fusão de várias mídias em um suporte computacional, suportado por sistemas eletrônicos de comunicação e que podem ser utilizados na construção de ambiências pedagógicas que, aliadas à planificação das aprendizagens podem se constituir em excelentes coreografias de ensino convergentes.

A criação de novas estratégias pedagógicas, integrando as TDIC e a Web, com intencionalidade pedagógica e busca dirigida das informações na convergência entre dispositivos tecnológicos virtuais e presenciais, pode transferir tecnologias específicas às áreas de conhecimento envolvidas na formação docente e imprimir aos processos de aprendizagem a mediação de tecnologias cognitivas, - ou seja, atuam como "ins- 
trumentos de mediação sociocultural" (Vygotski, 1993, 1995) nos processos formativos iniciais e ao longo da vida, favorecendo ao professor a reflexão na/sobre a sua prática.

Os saberes docentes, em constante formação e inter-relacionados à qualificação das condições objetivas para a ambiência pedagógica digital $^{8}$, também a partir das condições necessárias para a formação em exercício, incluem tempo disponível para formação, promoção de trabaIho coletivo, bem como a gestão e organização do trabalho docente. Isto poderá ser boa parte do caminho para a resiliência digital docente, ou seja, a adaptação consciente e ativa dos docentes que estão enfrentando uma multiplicidade de desafios adaptativos às tecnologias digitais como elementos importantes na planificação e desenvolvimento do trabalho docente frente aos desafios do Século XXI.

\section{Processo metodológico da pesquisa}

Trata-se, epistemologicamente, de pesquisa com abordagem qualitativa, em que o interpretativismo ou construtivismo, relativiza o saber, entendido pelo ponto de vista individual daqueles diretamente envolvidos. Assim, os sujeitos desenvolvem significados subjetivos de suas experiências, atribuindo significados para alguns objetos ou coisas (Creswell, 2010). Interpreta-se os acontecimentos e entende-se as relações existentes entre os constructos a partir da ótica dos pesquisadores, considerando os seus estilos e expertises ao moldar as interpretações durante o estudo (Creswell, 2010).

Ao buscar-se o mapeamento de 26 cursos diferentes de licenciatura, optou-se pelo estudo de casos múltiplos (Yin, 2005), com triangulação de dados, porém sem a intenção deliberada de comparar os resultados. Os casos são mapeados e estudados pela natureza de suas atividades e cultura profissional, reunindo-se informações detalhadas com múltiplos procedimentos durante um período de tempo prolongado. A estratégia narrativa também permite estudar-se abordar a vida e professoralidades dos professores, ao contarem as suas trajetórias e experiências.

8 A ambiência pedagógica digital se configura como contexto educativo com acessibilidade às tecnologias digitais e a Web, usados como instrumentos socioculturais de mediação. Nele são vivenciadas as condições de protagonismo efetivadas na cultura de colaboração e atividade compartilhada entre nativos e imigrantes digitais (Da Rocha, 2014). 
A pesquisa envolve os vinte e seis (26) cursos de licenciaturas presenciais da UFSM, escolhidos por serem totalmente gestados pela Instituição, com características administrativas similares. São eles: Artes Visuais, Desenho e Plástica; Dança, Licenciatura; Educação Física Licenciatura; Letras Espanhol e Literaturas de Língua Espanhola, Noturno; Letras Inglês e Literaturas de Língua Inglesa; Letras Português e Literaturas de Língua Portuguesa; Música; Teatro; Ciências Biológicas (sede e CESNORS); Física Diurno; Física Noturno; Matemática Diurno; Matemática - Noturno; Química; Ciências Sociais Noturno; Filosofia; Geografia; História; Educação Especial Diurno; Educação Especial Noturno; Pedagogia Diurno; Pedagogia Noturno; Programa Especial de Graduação (PEG) - Formação de Professores para a Educação Profissional; Educação Física. Os cenários da pesquisa são organizados por distintos grupos de formadores e de professores em formação, cursos e unidades de ensino, justificando a escolha de estudo de casos como metodologia, uma vez que "investiga um fenômeno contemporâneo dentro de seu contexto da vida real" (YIN, 2005, p. 32).

Portanto, em cada cenário, estão sendo convidados a participar de modo livre e esclarecido: a) professores de licenciatura com vínculo efetivo à Instituição pesquisada; na etapa exploratória (atual) todos os professores dentro dessas características podem responder o formulário; na etapa narrativa, participam os professores que efetivamente desenvolvem experiências com TDIC/WEB em suas práticas docentes; b) estudantes das licenciaturas regularmente matriculados na Instituição e cursando os semestres finais do curso $\left(5^{\circ}\right.$ a $8^{\circ}$ semestre), porque neste período geralmente desenvolvem práticas educativas e estágios supervisionados nas escolas parceiras.

Busca-se, de um modo abrangente, compreender: a) como se interconectam: processos formativos iniciais dos licenciandos; processos auto(trans)formativos dos formadores; e saberes docentes das TDIC e da Web nos cursos de licenciatura presenciais da UFSM? e b) quais os indicativos de convergência digital e tecnológica para a Educação Básica a partir da integração universidade-escola, dentre outros, nas práticas educativas e estágios supervisionados? Para isso, representam aspectos pontuais da investigação empírica:

- Mapeamento das licenciaturas presenciais da UFSM no que se refere à: relevância da CC e significativa presença dos saberes docentes das TDIC/da Web nos Projetos Pedagógicos de Curso (PPC); 
La cultura de convergencia digital y la inclusión sociocultural: Interconectando formación y práctica docente

adriana Moreira Da Rocha y Doris Pires Vargas Bolzan

integração do Moodle (Modular Object-Oriented Dynamic Learning Environment $)^{9}$, das TDIC e da Web nas pedagogias universitárias em desenvolvimento nos processos formativos dos licenciandos; atenção as demandas auto(trans)formativas dos formadores (fluências pedagógica e tecnológica).

- Indicativos da influência das experiências docentes de convergência digital e tecnológica nos processos auto(trans)formativos na/da docência nos cursos de licenciatura.

- Identificação de possíveis repercussões de tais experiências na inserção dos estudantes na Educação Básica, por meio da aplicabilidade da CC nas práticas educativas e estágios supervisionados.

- Levantamento de indicativos de convergência na formação inicial de professores a partir das experiências de estudantes de licenciaturas em processos de integração universidade-escola.

O estudo está organizado em quatro fontes distintas. A primeira fonte decorre de estudos bibliográficos para o conhecimento atual do tema, com busca sistemática de aportes teóricos e metodológicos e círculos de leitura reflexiva desenvolvido pela equipe de pesquisa.

A segunda fonte advém da análise documental das políticas educativas e institucionais, legislações e documentos. A busca pelos documentos definidores de políticas educacionais, legislações e projetos pedagógicos de curso trazem subsídios para a descrição e compreensão da organização dos processos formativos nos diferentes cenários, permitindo também o mapeamento das propostas curriculares em busca dos identificadores de CC.

Na terceira fonte, desenvolveram-se os estudos exploratórios, como fase inicial da coleta de dados, para mapeamento dos cursos de licenciatura e também para identificar os sujeitos (docentes e discentes) que por adesão participarão na reconstrução narrativa. Estão sendo enviados/ analisados formulários, a partir do Google Drive, ferramenta Web 2.0, com respostas dissertativas e de múltipla escolha, a partir dos seguintes tópicos: características pessoais e de formação acadêmica do sujeito; opção pela carreira docente; desenvolvimento da fluência pedagógica/ tecnológica; percepções do currículo do curso frente à CC; experiências

9 O Moodle é um software livre executado em ambiente virtual, contando com um Sistema de gestão da aprendizagem (Learning Management System), acessível por meio da Internet ou de rede local. Site oficial: < https://moodle.org/>. 
significativas com as tecnologias digitais e a web no processo de ensino e aprendizagem; aplicabilidade dos saberes das TDIC e da WEB nas pedagogias convergentes, na formação e na Educação Básica.

A quarta fonte aprofunda a abordagem investigativa, por meio das entrevistas narrativas com docentes que manifestaram disponibilidade para a(s) interação(ões), realizando-se novos questionamentos e aprofundando questões levantadas no formulário, com foco no compartilhamento das experiências docentes. As entrevistas narrativas são gravadas em equipamento de gravação profissional e transcritas adequadamente, na íntegra, descrevendo-se as minúcias do processo de entrevista. O texto final é enviado ao entrevistado para que analise e complemente, se necessário, reconstruindo a narrativa e autorizando a utilização da mesma pelas pesquisadoras. Com relação às narrativas de formação, Josso (2004, p. 38) assevera que estas: "[...] servem de material para compreender os processos de formação, de conhecimento e de aprendizagem", proposição que justifica o percurso metodológico escolhido.

Quanto ao movimento analítico-interpretativo, o pensamento em circularidade (Morin, 1986, 1998, 2001, 2010) permitindo aos investigadores o movimento entre os achados de pesquisa permite compreender os contextos formativos em complexidade, reunindo as informações das diferentes fontes. Busca-se a circularidade de todas as informações, teóricas e empíricas, tendo como eixo os objetivos da pesquisa, gerando informações que vão sendo validadas, configurando o corpus da pesquisa ao integrar as identidades próprias a cada unidade simples e as identidades comuns nas propostas e experiências formativas, tecendo o conjunto complexo de cada parte (curso) e do todo (licenciaturas da UFSM).

As especificidades dos cursos estão correlacionadas no todo dos processos formativos institucionalizados, permitindo, assim, uma visão de complexidade dos achados: "a relação entre a parte e o todo, não é apenas a parte que está no todo, mas o todo que está igualmente na parte" (Morin, 2002, p. 14). A triangulação dos dados permite a construção/ reconstrução da teoria, em uma circularidade integrativa, buscando a unidade de pensamento nos diferentes elementos da pesquisa, tendo no pensamento complexo o fio de tecitura entre as informações advindas do conjunto dos cursos de licenciatura, entrelaçados à matriz teórica. 


\section{Entre resultados e discussões, a articulação entre a teoria e a prática}

Alguns achados da pesquisa já anunciam experiências de integração das tecnologias digitais e da WEB no curso de licenciatura em pedagogia, em disciplinas curriculares e de ambiência pedagógica digital nos processos formativos, principalmente na integração do ambiente virtual de ensino-aprendizagem Moodle no ensino presencial e, ainda, a análise das experiências de integração das tecnologias digitais e da WEB na inserção dos pedagogos em formação na Educação Básica, mediante estágios, oficinas e outras atividades.

A pesquisa ora apresentada e discutida deriva e converge para vários estudos, por nós orientados a partir da pesquisa mater: dissertações de mestrado (Buss, 2012; Nogueira, 2012; Becker, 2013; Barbiero, 2013; Enderle, 2014) e teses de doutorado (Barbiero, 2013; Nunes, 2012). Também se têm investigado as prováveis interconexões pedagógicas e tecnológicas da experiência docente nos ambientes Virtuais de Ensino Aprendizagem (AVEA), com relevância ao Moodle.

Tem-se identificado que os primeiros semestres das licenciaturas na UFSM estão sendo cursados em grande parte por jovens entre 16 e 17 anos, nascidos de 1997 para cá, portanto, nativos digitais (Prensky, 2001) e representantes da Geração Z (Tapscott, 1999, 2010).

Os resultados desses estudos também vêm apontando novos saberes docentes, a partir da integração das Tecnologias Digitais da Comunicação e Informação (TDIC adiante) e da Web (Barbiero, 2013) em novos saberes e novas coreografias de ensino; os processos de ensino e aprendizagem mediados pelo Moodle, dentre outras condições e ambientes imersivos (Buss \& Maciel, 2012), configuram uma ambiência interativa em que o computador é integrado como instrumento sociocultural de mediação, dando acesso não somente às informações, mas ao diálogo virtual com os demais participantes do curso ou disciplina.

Configura-se a ambiência humano-tecnológica, provida de movimentos cognitivos e afetivos. A ambiência humano-tecnológica foi por nós definida como um contexto biossistêmico e biotecnológico, envolvendo as condições internas (inter e intrapessoais) e externas (meio físico e tecnológico) na interação entre os seres humanos, no ciberespaço, mediados pelas TDIC e pela Web (Buss \& Maciel, 2012).

Constatou-se, também, a possibilidade de comunidades colaborativas 
de aprendizagem na EAD (Becker, 2013), a partir das redes de formação que essa modalidade possibilita aos cursos de formação de professores. No trabalho em rede, a docência virtual compartilhada (Nogueira, 2012) também tem sido um conceito-chave ao observar a interatividade de tutores e professores engajados nos processos formativos virtuais, viabilizando, inclusive, as próprias práticas educativas nos cursos de graduação a distância (Enderle, 2014).

Nos estudos citados observaram-se movimentos pedagógicos diferenciados na modalidade EAD, provocada pela integração das TDIC e dos ambientes virtuais na Web nos ambientes virtuais de ensino-aprendizagem (AVEA). Tomando-se como referência o Moodle, podem-se inferir implicações que a aprendizagem mediada pelas tecnologias digitais pode ter na modalidade presencial. Além das disciplinas, tarefas e notícias presentes no cotidiano, o Moodle pode representar importante avanço na Educação, desde que não seja visto como mero repositório de conteúdo, questionários e fóruns.

Os estudos permitiram algumas hipóteses de integração da experiência docente na modalidade EAD, migrando atividades e recursos das hipermídias para suas práticas na modalidade presencial: a oportunidade aberta a todos os docentes de integração do Moodle no ensino presencial de graduação e pós-graduação; integração de tecnologias cognitivas como instrumentos socioculturais de mediação às aprendizagens, fomentando-as de acordo com as necessidades das diferentes áreas do conhecimento; integração de caminhos da Web para busca, produção e compartilhamento de informações; comunicação e aprendizagens colaborativas, dentre outras. Tal integração tornaria viável a criação de pedagogias universitárias convergentes e a imigração digital docente, ou seja, a formação do formador e a aprendizagem da docência digital, como usuários das TDIC e da WEB, onde se tornam resilientes pela apropriação ativa dos saberes das TDIC e da Web: "o saber relacionado às possibilidades educativas da Web e o saber relacionado com a utilização/ integração das TDIC no processo de ensino e aprendizagem" (Barbiero, 2013, p.45).

O conceito de imigração digital docente supõe a passagem da cultura analógica para a cultura de convergência digital, considerando-a como processo de reconstrução dos saberes da docência, por meio da:

a) imersão na cultura de convergência digital (Jenkins, 2009), ou, na cibercultura, de acordo com a abordagem de Lèvy (2000, 2009, 
La cultura de convergencia digital y la inclusión sociocultural: Interconectando formación y práctica docente

adriana Moreira Da Rocha y Doris Pires Vargas Bolzan

2011) - para apreender o contexto cultural das gerações constituídas pelos estudantes, nativos digitais (Prensky, 2001) ${ }^{10}$ e para dominar os novos instrumentos socioculturais de mediação ao desenvolvimento e aprendizagem (Vygotski, 1995);

b) criação de novas estratégias pedagógicas, integrando as TDIC e as possibilidades virtuais da Web, com intencionalidade pedagógica e busca planejada das informações, planificadas em novas coreografias de ensino;

c) articulação de práticas formativas combinadas, ou seja, atividades presenciais e virtuais intercomplementares, permitindo ao estudante apreender a constituição das tecnologias educativas que depois, na Escola Básica, como professor, irá propor e desenvolver com as crianças e adolescentes.

Isto posto, o conceito de performance integrativa ${ }^{11}$ é definido como sendo a configuração de movimentos de convergência digital nas bases dos processos formativos de estudantes (professores em formação) e formadores. Em tais processos, a aprendizagem da docência promove intencionalmente a apropriação ativa dos saberes das TDIC e da Web ao longo do curso de formação e na transposição da formação inicial à formação continuada e práticas profissionais, integrados aos modos de ensinar e estilos de aprender no contemporâneo.

Pode-se inferir a possibilidade da aprendizagem da docência digital ${ }^{12}$ como um indicativo cultural que se destaca no contexto contemporâneo, com o qual a educação responde efetivamente ao desafio de educar as novas gerações dialogando com as suas inúmeras linguagens e atividades principais, destacando-se o domínio inteligente e colaborativo das tecnologias digitais e da Web.

10 O termo "nativo digital", cunhado por Prensky (2001) designa as pessoas que nasceram e cresceram com as tecnologias digitais presentes em seu cotidiano e, quando aplicado em contextos educativos, relaciona-se ao termo "aprendizes do novo milênio".

11 Performance integrativa é o termo criado pelas autoras para designar a configuração de movimentos de convergência digital nos processos formativos docentes, com propostas e práticas integrativas de diferentes hipermídias e dispositivos digitais.

12 Aprendizagem da docência digital caracteriza-se pelos modos de organização de dinâmicas pedagógicas midiáticas, cujo dinamismo revela avanços e retrocessos, rupturas e resistências na produção de saberes e fazeres docentes. Logo, o processo constitutivo de ser professor parte de uma ambiência em que há possibilidade de explicitação de diferentes movimentos na e da professoralidade (Bolzan, 2012, p.244245). 
As possibilidades de aprendizagem da docência digital nos processos formativos de estudantes e formadores são consideradas a partir das duas performances integrativas - as transformações qualitativas na universidade e as transformações qualitativas na escola, ou seja, duas faces de uma mesma moeda, constituindo a Educação no Século XXI:

1. Transformações qualitativas no contexto universitário - cursos superiores de formação de professores - a convergência digital, integra os saberes docentes das TDIC e Web em um continuum de experiências diversificadas, nos processos formativos iniciais dos estudantes e nos processos auto (trans) formativos dos formadores.

2. Transformações qualitativas no contexto escolar - níveis de ensino da Educação Básica - a convergência digital depende, mais do que da transferência de tecnologias de última geração, de professores cujas boas práticas derivam de aprendizagens que integraram as fluências tecnológica e pedagógica, ou seja, derivadas de processos formativos exitosos.

Nessa perspectiva pode-se afirmar que a de cultura de colaboração ${ }^{13}$ e a aprendizagem docente ${ }^{14}$ são elementos chave para a consolidação da aprendizagem da docência digital, tanto na educação básica como na educação universitária.

Existem situações em que a cultura de convergência digital tem ressonância em propostas e processos formativos, trazendo o conhecimento de como está acontecendo a convergência digital e tecnológica nos cursos de graduação que formam professores. Também situações de aparente convergência, em que o tecnológico e o pedagógico se encontram em descompasso, apontando elementos de transição para a apropriação das tecnologias cognitivas digitais pela educação ou, ainda, situações de total divergência, em que se permanece alheio ao compasso cultural em que as novas gerações estão nascendo e se desenvolvendo.

A sequência de pesquisas e o avanço teórico da área traz a urgência

13 Cultura de colaboração é compreendida como o processo gerativo, por meio do qual o grupo dinamiza respostas $\backslash$ propostas coletivas aos inúmeros desafios profissionais, configurando uma cultura própria. (Bolzan, 2013, p.01).

14 Aprendizagem docente caracteriza-se pelos modos de construção e produção da docência, ou seja, os modos de aprender e se fazer professor. É um processo tecido a partir de movimentos oscilatórios da aprendizagem docente cujo dinamismo revela avanços e retrocessos, rupturas e resistências na produção de saberes e fazeres docentes. (Bolzan, 2013, p.10). 
de se compreender as inter-relações entre a formação inicial dos professores na universidade, a formação permanente dos seus formadores e a integração das TDIC e da Web. A partir da Cultura de Convergência Digital alinham-se novas formas de lidar com as informações e, consequentemente de produzir conhecimentos, provocando a [re] construção da docência na Educação Superior e na educação Básica, sob novos paradigmas e novos saberes convergentes.

\section{Apontamentos finais: à guisa de conclusão}

O amadurecimento profissional e a consciência de que a aprendizagem da docência é um processo construído ao longo da carreira é um elemento distintivo no contexto da formação inicial de professores. Este processo depende de que os professores possuam um conhecimento consistente da sua área, do modo como seus alunos aprendem em uma cultura digital colaborativa e de como podem ser auxiliados neste processo, o que, sem dúvida, mobiliza movimentos de reorganização do trabalho pedagógico nos saberes e fazeres da docência, a começar nos cursos de formação de professores, ou seja, nas universidades.

Retomando-se as premissas da pesquisa, o mapeamento das licenciaturas presenciais da UFSM vem apontando que:

- Ainda é singela a presença da CC e dos saberes docentes das TDIC/ da Web nos Projetos Pedagógicos de Curso (PPC);

- Embora a instituição ofereça suporte tecnológico e treinamento, a integração do Moodle e o uso das TDIC e da Web nas pedagogias universitárias em desenvolvimento nos processos formativos dos licenciandos ainda são muito modestos;

- A instituição promove eventos de treinamento e formação, tendo em vista a atenção às demandas auto(trans)formativas dos formadores (fluências pedagógica e tecnológica), no entanto, ainda não se observa um movimento auto(trans)formativo coletivo neste sentido.

Os estudos exploratórios e as entrevistas, ainda em desenvolvimento, já apresentam alguns indicativos da influência das experiências docentes de convergência digital e tecnológica nos processos auto(trans) formativos na/da docência nos cursos de licenciatura. Pode-se observar 
propostas de estágios no curso de pedagogia levados a cabo com coreografias didáticas digitais interessantes, identificando-se a possibilidade positiva de possíveis repercussões das experiências formativas na inserção dos estudantes na Educação Básica, por meio da aplicabilidade da CC nas práticas educativas dos estudantes em estágio.

Quanto ao levantamento de indicativos de convergência na formação inicial de professores a partir das experiências de estudantes de licenciaturas em processos de integração universidade-escola, este é um mote ainda a ser alcançado, pois será resultante da triangulação final dos dados.

Tem-se observado que mesmo na tentativa de serem docentes "on-line", reproduzindo o que acontece no ensino presencial, os professores deparam-se com situações e necessidades diferentes e têm a possibilidade de [re]planejar e [re] inventar modos de fazer e saber no cotidiano pedagógico. No decorrer desse processo constitutivo, de forma gradativa, vão se reconhecendo como e por que elegem tal recurso ou ferramenta ao compor uma coreografia de ensino com os estudantes, qual a melhor forma de expressão comunicativa, recursos disponíveis e condições para a construção de uma ambiência digital e como mediarem culturalmente novas e significativas aprendizagens.

Com relação à construção de novos saberes da docência, cabe observar-se que as narrativas docentes, deste estudo, confirmam de modo empírico a existência e a reconstrução de saberes emergentes, como o saber relacionado às possibilidades educativas da WEB e o saber relacionado com a utilização/integração das TDIC nos processos de ensinar e de aprender. (Barbiero, 2013).

A Era da Informação segue o seu percurso, mesmo que em paralelo o mundo analógico ainda seja reverenciado e isto na educação reforça a posição anacrônica daqueles que seguem alheios às rupturas que já se fazem no modo humano de interagir e comunicar. Portanto, urge aceitar o desafio de abraçar a mudança de paradigma, a fim de trazer esses novos vernáculos para os meios acadêmicos e escolares, de modo a estabelecer formas criativas de pensar e desenvolver a formação de professores.

Assim, a reflexão empreendida até o presente permite afirmar que uma proposta coerente para a formação dos professores na/da educação superior precisa configurar-se como: [1] formação tecnológica com base nas atividades de iniciação científico-tecnológica; [2] inclusão sociodigital; [3] formação ético-político-cultural para o exercício do profis- 
La cultura de convergencia digital y la inclusión sociocultural: Interconectando formación y práctica docente

Adriana Moreira Da Rocha y Doris Pires Vargas Bolzan

sionalismo solidário e da cidadania; [4] formação profissional voltada à aprendizagem da docência digital, articulando fluência pedagógica e tecnológica.

Logo, a transição de paradigmas envolve a compreensão dos modelos que ainda aprisionam à tradição e por que é preciso superá-los e também de novos modelos que compreendem as tecnologias digitais como instrumentos socioculturais de mediação pedagógica. Nesse processo, mudar por mudar pode ser opção arriscada, pois é preciso transformar, o que exige decisão e coragem para romper com velhos padrões e instituir o "novo".

No entanto, esse parece ser o caminho da inovação pedagógica, onde a cultura de convergência digital traz à educação questões a serem aprofundadas e refletidas, cujas alternativas devem ser buscadas no protagonismo tanto do docente como do discente. Esse processo depende de que os professores se insiram juntamente com os estudantes em uma cultura digital colaborativa, o que, sem dúvida, mobiliza movimentos de desconstrução e reconfiguração das propostas formativas das quais participam ou participaram.

\section{Referências bibliográficas}

BAERISWYL, F. (2008). New choreografies of teaching in higher education. $V$ Congreso Iberoamericano de Docencia Universitaria, Espanha, Valência. Acessado 20/06/2014 desde http://redaberta.usc.es/aidu/index2.php?option=com_docman\&task=doc_ view\&gid=157\&ltemid $=8$.

BARBIERO, D. R. (2013). Entre o Presencial e o Virtual: Movimentos em Direção a Novos Saberes da Docência Superior. Dissertação de Mestrado. Santa Maria: UFSM/PPGE.

BECKER, A. M. (2013). Constituição de comunidade: [im]possibilidades no percurso formativo em EAD. Dissertação de Mestrado. Santa Maria: UFSM/PPGE.

BOLZAN, D. P. V. (2009). Formação de professores: compartilhando e reconstruindo conhecimentos (pp.174). Porto Alegre: Ed. Mediação.

. (2008a). Aprendizagem colaborativa: processos formativos em construção. Anais do VII Seminário de Pesquisa em Educação da Região Sul (ANPEd SUL) (pp. 01-15). Itajaí.

(2008b). Pedagogia Universitária e processos formativos: a construção de conhecimento pedagógico compartilhado. Trajetórias e processos de ensinar e aprender: didática e formação de professores (pp. 102-120). Porto Alegre: EDIPUCRS.

.(2009). Aprendizagem docente e processos formativos: novas perspectivas para educação básica e superior. Relatório Final de Pesquisa, Registro no GAP no 020117. CNPq/PPGE/CE/UFSM. 
La cultura de convergencia digital y la inclusión sociocultural: Interconectando formación y práctica docente Adriana Moreira Da Rocha y Doris Pires Vargas Bolzan

. (2012). Aprendizagem docente: movimentos da professoralidade no ensino superior. In: PULLIN, E. M. M. P.; BERBEL, N. A. N.(Orgs.). Pesquisas em Educação: inquietações e desafios. pp.564). Londrina: EDUEL.

(2013). Aprendizagem docente e processos formativos: movimentos construtivos da professoralidade na educação básica e superior. Relatório Final de Pesquisa. Bolsa PQ 10/2009, n 304863/2009-2, GAP/CE/UFSM.

. (2014). Aprendizagem da Docência: processos formativos de estudantes e formadores da educação superior. Relatório Parcial de Pesquisa, Bolsa Pq, n032835, GAP/ CE/UFSM, 2013-2015.

BUCKINGHAM, D. (2010). Cultura. Digital, Educação Midiática e o Lugar da Escolarização. Revista Educ. Real., (pp. 37-58). Porto Alegre, 35(3). Acessado 20/08/2014 desde http://www.ufrgs.br/edu_realidade.

BUSS, A. M. (2012). Formação Inicial de Pedagogos na Modalidade EAD - Estudo no Âmbito do Sistema UAB. Dissertação de Mestrado. Santa Maria: UFSM/PPGE.

BUSS, A. M. MACIEL, A. M. R. (2012). Ambiência humano-tecnológica em contextos biossistêmicos. Um design conceitual (pp. 1-4). 27ª Jornada Acadêmica Integrada, Santa Maria, 2012.

CRESWELL, J. W. W. (2010). Projeto de pesquisa: métodos qualitativo, quantitativo e misto. 2. ed.Porto Alegre: Bookman.

DA ROCHA, A. M. R. (2014). A [re] construção da docência superior nas interconexões entre ambientes formativos presenciais e virtuais. Projeto de Pesquisa $\mathrm{n}^{\circ} 0333451$, GAP/CE/UFSM, 2013-2015.

DALEY, E. (2010). Expandindo o conceito de letramento. Trabalhos em Linguística Aplicada (pp. 481-491). Campinas, 49(2).

DAVÍDOV, V. SHUARE, M. (1987). La Psicologia y Pedagogia em La URS (pp. 316-337). Moscú: Progreso.

ELKONIN, D. B. (1998). Psicologia do jogo. São Paulo: Martins Fontes.

ENDERLE, M. G. (2013). Entre anseios e descobertas: o estágio supervisionado do Curso de Pedagogia a Distância UAB/UFSM. Dissertação de Mestrado. Santa Maria: UFSM/ PPGE.

FREIRE, Paulo. (1987). Pedagogia do Oprimido. 29 ed. Rio de Janeiro: Paz e Terra.

GARCIA, C. M. (1999a). Formação de professores: para uma mudança educativa. Portugal: Editora Porto.

. (1999b). Formación del professorado para el cambio educativo. Barcelona: EUB.

HAYASHI, C. R. M. SANTOS, V. W. O. (2009). Apropriação social das TICs: cidadania e Inclusão sociodigital com o Programa GESAC. Revista Tecnologia e Sociedade, Curitiba, v. 5, n. 9, jul./dez. 17p.

JENKINS, H. (2009). Cultura da convergência. São Paulo: Aleph.

LÉVY, P. (2009). Cibercultura. São Paulo: Editora 34.

. (2011). The Semantic Sphere 1: Computation, Cognition and Inormation EConomy. New Jersey, USA: Wiley-ISTE.

. (2014). A Esfera Semântica: Tomo I Computação, Cognição e Economia da Informação. São Paulo: Annablume.

MACIEL, A. M. R. (2000). Formação na docência universitária? Realidade e possibili- 
La cultura de convergencia digital y la inclusión sociocultural: Interconectando formación y práctica docente

adriana Moreira Da Rocha y Doris Pires Vargas Bolzan

dade na docência universitária? Realidade e possibilidades a partir do contexto da Universidade de Cruz Alta. Tese de Doutorado. Campinas: Universidade Estadual de Campinas, São Paulo.

MACIEL, A. (2006). Verbetes. In: MOROSINI, M. (ed.). Enciclopédia de Pedagogia Universitária: Glossário(pp.351). Brasília: INEP.

. (2009). O processo formativo do professor no ensino superior: em busca de uma ambiência (trans)formativa. In ISAIA, S. M. de A. BOLZAN, D. P. V. B. MACIEL, A. M. da R. (orgs.). Pedagogia Universitária tecendo redes sobre a educação superior. Santa Maria: Editora UFSM, pp.63-77.

MACIEL, A. M. R. ISAIA, S. M. A. (2013). Pedagogia Universitária: construções possíveis nas diferentes áreas de conhecimento. $36^{a}$ Reunião Nacional da ANPEd, Goiânia.

NOGUEIRA, V. S. (2012). Práticas pedagógicas na educação a distância: deslocamento de memórias e de sentidos. Dissertação de Mestrado. Santa Maria: UFSM.

NÓVOA, A (org.). (1992). Os Professores e a sua formação. Lisboa: Nova Enciclopédia, publicações Dom Quixote.

OSER, F. K.; BAERISWAYL, F.J. (2001). Choreografies of teaching: bridging instruction to teaching. In RICHARDSON, V. (org). Handbook of research on teaching. Washington: American Educational Research Association.

PRENSKY, M. (2001). Digital natives, digital immigrants. On the Horizon, 9(5).

(2010). O papel da tecnologia no ensino e na sala de aula. Conjectura, v.15, n. 2, pp. 201-204. Acessado 04/09/2014 desde <http://www.ucs.br/etc/revistas/index. php /conjectura/article/viewFile/335/289>.

TAPSCOTT, D. (1999). Geração Digital: a crescente e irreversível ascensão da geração net. São Paulo: Makron Books. (2010). A Hora da Geração Digital. Rio de Janeiro: Agir.

VIERA TREVISAN, N. DA ROCHA, A. M. (2014). Resiliência Docente: Ambiência [Trans] formativa na Educação Superior. Curitiba: CRV.

VYGOTSKI, L.S. (1993). Problemas de psicologia general. Madrid: Visor.

VYGOTSKI, L.S. (1995). Obras escogidas - Tomo III. Madrid: Visor Distribuiciones. (2003). Imaginación y creación em La edad infantil. Buenos Aires: Nuestra América.

YIN, R.K. (2005). Estudo de caso: planejamento e métodos. 3. ed. Porto Alegre: Bookman,

\section{Nota de agradecimento}

Registra-se o apoio financeiro do CNPq - Conselho Nacional de desenvolvimento Científico e Tecnológico ao desenvolvimento das pesquisas "Cultura de convergência digital nos cursos de licenciatura da UFSM: é possível uma conexão (trans)formativa entre a Educação Superior e a Educação Básica?" e "Aprendizagem da docência: processos formativos de estudantes e formadores da educação superior". 